\title{
Thermal Decomposition of Flexible Polyurethane Foams in Air
}

\author{
Pau D.S.W. ${ }^{1,}{ }^{*}$, Fleischmann C.M. ${ }^{1}$, Delichatsios M.A. ${ }^{2}$ \\ ${ }^{1}$ University of Canterbury, Christchurch, Canterbury, New Zealand \\ ${ }^{2}$ Northeastern University, Boston, Massachusetts, USA \\ *Corresponding author's email: dennis.pau@canterbury.ac.nz
}

\begin{abstract}
The oxidative thermal decomposition of a non-fire retardant and a fire retardant polyurethane foam is investigated over $1-60{ }^{\circ} \mathrm{C} / \mathrm{min}$ of heating rate. From the thermogravimetry results under the oxidative environment of air, additional oxidative reactions which are heating rate dependent compete with the pyrolysis reactions over similar temperature range. The decomposition behaviour differs for the foams and the heating rates investigated. Due to the presence of fire retardant additives, the oxidative thermal decomposition from heating rates of $1-20{ }^{\circ} \mathrm{C} / \mathrm{min}$ occurs at a higher rate and over a narrower temperature range for the fire retardant foam. However, at $60{ }^{\circ} \mathrm{C} / \mathrm{min}$, the fire retardant foam shows a reduced decomposition rate spreading over a wider temperature range. This shows the fire retardant foam can decompose rapidly at low heating rate, under the condition of low temperature with ample of oxygen. This is similar to the incipient phase of a fire, and ignition inhibition is possible when coupled with the gas phase fire retardant mechanisms of the fire retardant foam. The char residue formed by the solid phase fire retardant mechanism slows the decomposition rate, and as the heating rate increases, the decomposition extends over a greater temperature range due to improved thermal stability. For both foams, the increase in heating rate shows a gradual reduction to the influence from oxidative reaction of foam, shifting towards the pyrolysis reaction of polyol. Kinetic properties of Arrhenius equation governing the decomposition rate are estimated graphically using the Inflection Point Methods and the model shows reasonable agreement with the experimental results. From the heat flow results, the heat of reaction for the oxidative thermal decomposition of foams is calculated and is found to be exothermic.
\end{abstract}

KEYWORDS: Kinetic properties, oxidative thermal decomposition, polyurethane foam, DSC, TGA.

\section{INTRODUCTION}

During smouldering combustion, condensed solid undergoes decomposition which is chemically more complex when compared to flaming combustion. This is caused by the presence of oxygen which results in additional oxidative reactions that compete with the pyrolysis reactions in smouldering combustion. A number of researchers have presented the science and physical phenomena in great details relating to smouldering combustion [1-5]. In flaming combustion, the oxygen is mostly consumed in the gas phase, producing flame which is an oxidative reaction zone [6]. While this assumption is valid for most condensed solid, the porous nature of flexible polyurethane (PU) foam allows oxygen to permeate the material by means of convection and diffusion hence the influence of oxidative reactions in flaming combustion could be significant [7].

A number of researchers have demonstrated that the thermal decomposition behaviour of flexible PU foam in air is more complex than under an inert environment [7-13]. These researchers have estimated the kinetic properties governing the decomposition via graphical method or genetic algorithm; however, the information is scarce as the studies mainly involved flexible foam without fire retardant additives, and at relatively low heating rates, below $20{ }^{\circ} \mathrm{C} / \mathrm{min}$ in comparison with heating rate achieved in flaming combustion, $200-400{ }^{\circ} \mathrm{C} / \mathrm{min}$. Based on the thermogravimetry 
(TG) results [9], Rein et al. [10] proposed a 2-step pyrolysis mechanism to describe the thermal decomposition of flexible foam under inert nitrogen environment, and included 3 additional oxidative reactions for the decomposition under oxidative air environment. The proposed 5-step oxidative decomposition mechanism was further validated by Valencia et al. [11, 12] and Rogaume et al. [13] via detailed experimental studies involving Thermogravimetric Analysis (TGA), Differential Scanning Calorimetry (DSC), tubular furnace and Fourier Transform Infra-Red (FTIR) spectroscopy, leading to an improved understanding of the competition between pyrolysis and oxidative reactions and the characterisation of the gaseous products released during each macroscale decomposition step. Krämer et al. [7] demonstrated that the oxidative decomposition behavior changes with heating rate, and for heating rate experienced in flaming combustion, the 2-step mechanism was found to dominate under both nitrogen and air environments.

This paper aims to supplement the current knowledge on oxidative thermal decomposition of PU foam by presenting the experimental study on a non-fire retardant (NFR) and a fire retardant (FR) foam using Simultaneous Differential Scanning Calorimetry and Thermogravimetry Analysis (SDT), at four different heating rates, $1,5,20$ and $60^{\circ} \mathrm{C} / \mathrm{min}$, under inert nitrogen environment and oxidative air environment. The kinetic properties consisting of reaction order $(n)$, pre-exponential factor $(A)$ and activation energy $(E)$, relating to the oxidative and pyrolysis reactions are established using the Inflection Point Methods [14] from the temperature varying TG results. The heat of reaction $\left(\Delta h_{r}\right)$ relating to the oxidative thermal decomposition is established from the heat flow measurements attained from DSC.

\section{EXPERIMENTAL TECHNIQUE AND POLYURETHANE FOAM SELECTION}

The instrument used is SDT 600, a product of TA Instruments which simultaneously acquires both DSC and TGA measurements from the same sample. The experiments were conducted in dynamic mode where the foam sample was subjected to a constant heating rate within a purged furnace from room temperature $\left(20{ }^{\circ} \mathrm{C}\right)$ up to a maximum of $600{ }^{\circ} \mathrm{C}$ for inert nitrogen environment and $900{ }^{\circ} \mathrm{C}$ for oxidative air environment. The sample mass ranged between 3 and $4 \mathrm{mg}$, comprising shredded flexible foam fragments within a half-filled $90 \mu \mathrm{L}$ alumina cup. The sample was tested in open configuration without the presence of a lid to allow the release of volatiles from decomposition. The relatively small sample size ensures negligible thermal gradient spatially through the specimen during the transient heating process thus satisfying the assumption of a lumped capacitance system. The TGA measurements are the changes in sample mass during decomposition, registered based on the current signal required to correct a taut-band meter movement. The DSC measurements are the changes in enthalpy, registered based on the heat flux concept where the heat flow is determined from the changes in sample temperature according to the thermal equivalence of Ohm's Law. The heating rates investigated were $1,5,20$ and $60{ }^{\circ} \mathrm{C} / \mathrm{min}$, and for each heating rate, three replicates were tested. The selected heating rates were limited by the allowable maximum of the instrument at $100{ }^{\circ} \mathrm{C} / \mathrm{min}$.

The flexible PU foams investigated are referred to as NFR-SB-31 for the non-fire retardant foam with a density of $31 \mathrm{~kg} / \mathrm{m}^{3}$ and FR-Y-36 for the fire retardant foam with a density of $36 \mathrm{~kg} / \mathrm{m}^{3}$. The polyurethane foams are manufactured from the polycondensation of toluene diisocyanate, water and polyalkoxy polyether polyol. The polyol also contains styrene and acrylonitrile polymer. In smaller quantity, other ingredients include inorganic fillers, plasticisers, extenders, antimicrobial agents and pigments. The fire retardant additives within FR-Y-36 comprise melamine and halophosphate which have solid and gas phase fire retardant capability. In the gas phase, chlorine from the breakdown of halophosphate neutralises the reactive radicals produced by foam decomposition [15] while the breakdown of melamine also releases ammonia and nitrogen gas which dilute the concentration of combustible gas to inhibit combustion [16]. Melamine and phosphate structure are also reactive 
towards the gaseous isocyanates released, forming residue hence reducing the quantity of isocyanates available for gas phase combustion $[17,18]$. In the solid phase, melamine reacts with phosphoric acid from halophosphate breakdown to form thermally stable cross-linked residue or char at varying temperatures, melam at $350{ }^{\circ} \mathrm{C}$, melem at $450{ }^{\circ} \mathrm{C}$ and melon at $600{ }^{\circ} \mathrm{C}$ [19]. Further details relating to the experimental technique, calibrations and selection of flexible PU foams have been documented in a few publications for reference [20-22].

\section{PYROLYSIS AND OXIDATIVE REACTIONS OF POLYURETHANE FOAM THERMAL DECOMPOSITION}

Thermal decomposition of PU foam is described by the plot of decomposition rate, $d \alpha / d T$ versus reaction temperature, $T$ where a peak over a defined temperature range signifies the occurrence of a solid phase reaction. $\alpha$ is defined as the fraction decomposed and the decomposition rate is normalised by dividing $d \alpha / d t$ by the heating rate $\beta$. The decomposition behaviour of NFR-SB-31 is shown in Fig. $1 \mathrm{a}-\mathrm{d}$ for the different heating rates while the different line types on each plot denote the different environments, solid line represents air, dashed line represents nitrogen and dotted line represents the derived oxidative reactions. Decomposition under nitrogen environment shows a consistent 2-step pyrolysis mechanism at all heating rates as follow [13].

(1) PU Foam $\rightarrow$ Regenerated Polyol + Gaseous Isocyanates

(2) Regenerated Polyol $\rightarrow$ Char $+\mathrm{OH}$ Species, $\mathrm{H}_{2} \mathrm{CO}, \mathrm{CH}_{4}$ and $\mathrm{H}_{2} \mathrm{O}$

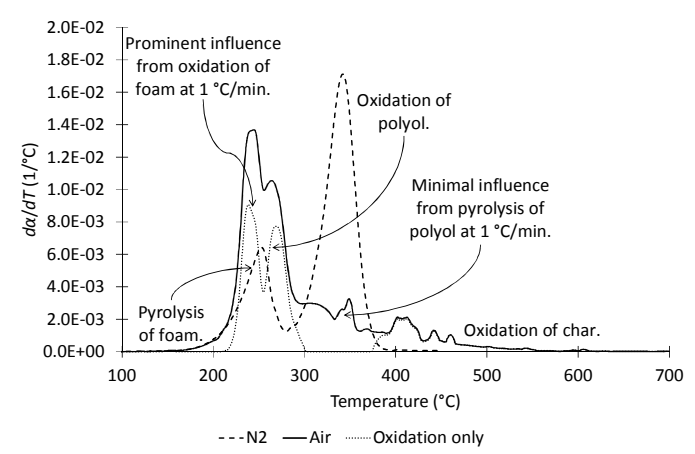

(a)

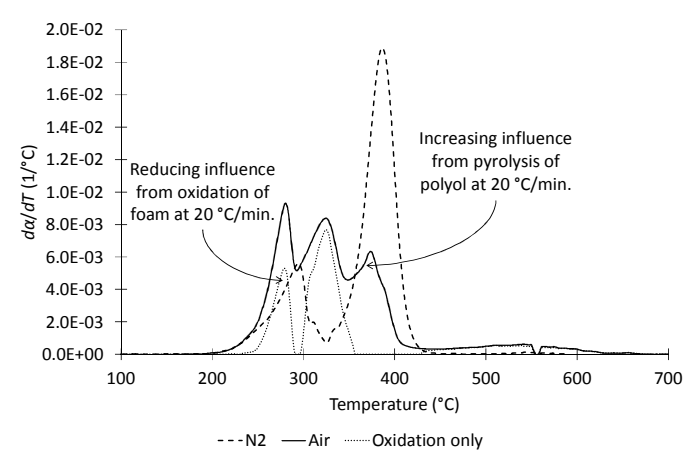

(c)

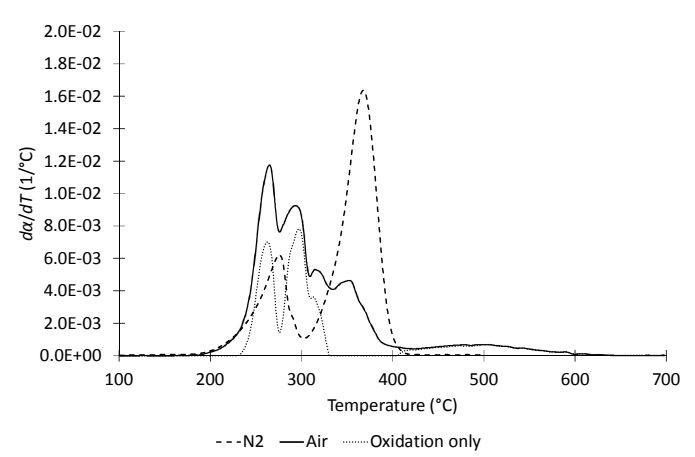

(b)

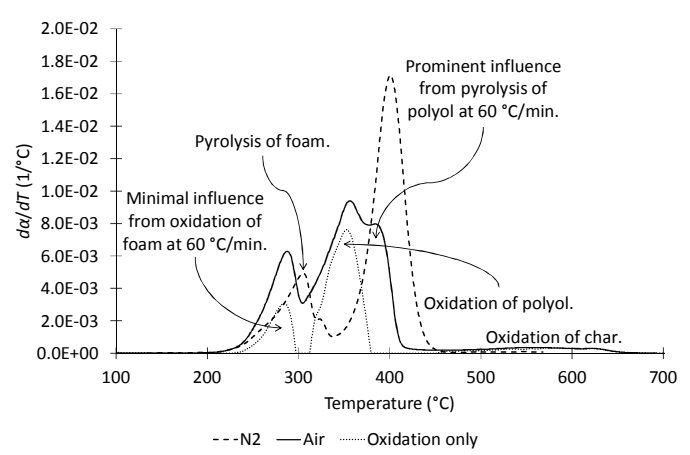

(d)

Fig. 1. Decomposition rate versus temperature of NFR-SB-31 in air and nitrogen, and the derived oxidative reactions. (a) $1{ }^{\circ} \mathrm{C} / \mathrm{min}$; (b) $5{ }^{\circ} \mathrm{C} / \mathrm{min}$; (c) $20^{\circ} \mathrm{C} / \mathrm{min}$; (d) $60{ }^{\circ} \mathrm{C} / \mathrm{min}$. 
The decomposition under air environment shows the outcome of a series of reactions overlapping closely across similar temperature range. The decomposition behaviour is also heating rate dependent where the peak of the curve shifts towards higher temperature as the heating rate increases. Assuming that the 2 pyrolysis reactions proceed and remain unaffected by the additional oxidative reactions under air, subtracting the decomposition under nitrogen (dashed line) from that of air (solid line) and setting all negative values to zero, yields the derived oxidative reactions (dotted line). These derived results illustrate the presence of 3 additional oxidative reactions as follow [13] which produce final and secondary products similar to the pyrolysis reactions, and also the common products of combustion such as carbon monoxide and carbon dioxide.

(1) $\mathrm{PU}$ Foam $+\mathrm{O}_{2} \rightarrow$ Regenerated Polyol $+\mathrm{OH}$ Species, $\mathrm{CO}_{2}$ and $\mathrm{H}_{2} \mathrm{O}$

(2) Regenerated Polyol $+\mathrm{O}_{2} \rightarrow$ Char $+\mathrm{OH}$ Species, $\mathrm{H}_{2} \mathrm{CO}, \mathrm{CH}_{4}, \mathrm{CO}, \mathrm{CO}_{2}$ and $\mathrm{H}_{2} \mathrm{O}$

(3) Char $+\mathrm{O}_{2} \rightarrow$ OH Species, $\mathrm{H}_{2} \mathrm{CO}, \mathrm{CH}_{4}, \mathrm{CO}, \mathrm{CO}_{2}$ and $\mathrm{H}_{2} \mathrm{O}$

The pyrolysis and oxidation of foam overlap over a similar temperature range, competing for the same reactant. The oxidative thermal decomposition initiates with the pyrolysis of foam but the competing oxidative reaction is able to accelerate and reach its peak first. With increasing heating rate, the reduction of the influence from oxidative reaction of foam (dotted line) is noted where the peak value reduces from $\sim 9.1 \times 10^{-3}$ to $3.1 \times 10^{-3} 1 /{ }^{\circ} \mathrm{C}$. The competing reactions for foam are followed by the oxidation of foam decomposition product, polyol which shows a fairly consistent influence at all heating rates, $\sim 7.7 \times 10^{-3} 1 /{ }^{\circ} \mathrm{C}$. Similar to foam, there is also a competing pyrolysis reaction for polyol but this is sufficiently separated over a higher temperature range. As heating rate increases, the influence from the pyrolysis of polyol (solid line) becomes more prominent where the peak value increases from $\sim 2.3 \times 10^{-3}$ to $8.0 \times 10^{-3} 1 /{ }^{\circ} \mathrm{C}$. Lastly, the char from pyrolysis and oxidation of polyol undergoes oxidation, and its magnitude is relatively small compared to the other main reactions. Nonetheless, a reduction in the influence of char oxidation is noted as the heating rate increases. The sequence of pyrolysis and oxidative reactions for the oxidative thermal decomposition of NFR-SB-31 is found to be consistent with the literature [11-13].

The decomposition behaviour of FR-Y-36 for the different heating rates is shown in Fig. 2 a $-\mathrm{d}$ based on the same legends of NFR-SB-31 for the different environments. Note that the vertical axis of (a) and (b) have greater magnitude than (c) and (d). Similar to NFR-SB-31, the decomposition under nitrogen of FR-Y-36 shows the consistent 2-step pyrolysis mechanism at all heating rates. The decomposition under air also shows overlapping and heating rate dependent reactions but the 3 oxidative reactions are not always apparent, different from NFR-SB-31. At 1 and $5{ }^{\circ} \mathrm{C} / \mathrm{min}$, following the initial pyrolysis reaction of foam, a single peak is noted from the derived oxidative reactions suggesting that the oxidation of foam and polyol overlap each other closely. This is possibly due to the fire retardant additives within the foam, where the acidic condition generated by the breakdown of halophosphate and the reactivity of melamine towards the products of foam decomposition might have catalysed the oxidation of foam and polyol, allowing these to proceed at lower temperature under such heating rates $[17,18]$. This lowers the ignitability of the gaseous products released and also allows the gas phase fire retardant mechanisms via means of neutralisation and dilution to be more effective. At 20 and $60{ }^{\circ} \mathrm{C} / \mathrm{min}$, separated peaks are noted for the oxidation of foam and polyol, and the influence of these oxidative reactions has diminished with increasing heating rate, from $\sim 2.7 \times 10^{-2}$ at $1{ }^{\circ} \mathrm{C} / \mathrm{min}$ to $4.6 \times 10^{-3} 1 /{ }^{\circ} \mathrm{C}$ at $60{ }^{\circ} \mathrm{C} / \mathrm{min}$.

While the influence from pyrolysis of polyol is negligible at 1 and $5{ }^{\circ} \mathrm{C} / \mathrm{min}$, this has increased at higher heating rates but compared to NFR-SB-31, the peak of the reaction is not as apparent. The char oxidation shows a similar trend to NFR-SB-31 in relation to heating rate but with greater magnitude due to char formation from melamine. According to Chao et al. [4], oxidative reaction is believed to be favored by slow heating and comparing Fig. 1 and Fig. 2, the results support this, 
showing the oxidative reactions having greater influence than the pyrolysis reactions at low heating rate. The temperature range where the main reactions occurs is $\sim 200{ }^{\circ} \mathrm{C}$ for NFR-SB-31, consistently between 200 and $400{ }^{\circ} \mathrm{C}$ but for FR-Y-36, this range can vary from $\sim 100-250{ }^{\circ} \mathrm{C}$. The main reactions occur between 200 and $300{ }^{\circ} \mathrm{C}$ below $5{ }^{\circ} \mathrm{C} / \mathrm{min}$, between 200 and $400{ }^{\circ} \mathrm{C}$ at 20 ${ }^{\circ} \mathrm{C} / \mathrm{min}$, and increasing to between 200 and $450{ }^{\circ} \mathrm{C}$ at $60{ }^{\circ} \mathrm{C} / \mathrm{min}$. The extended temperature range of FR-Y-36 at high heating is due to the char formation from the breakdown of melamine which improves the thermal stability of the decomposing sample.

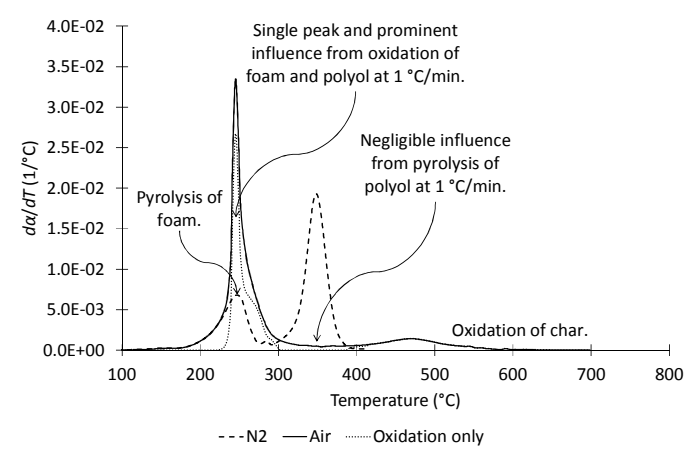

(a)

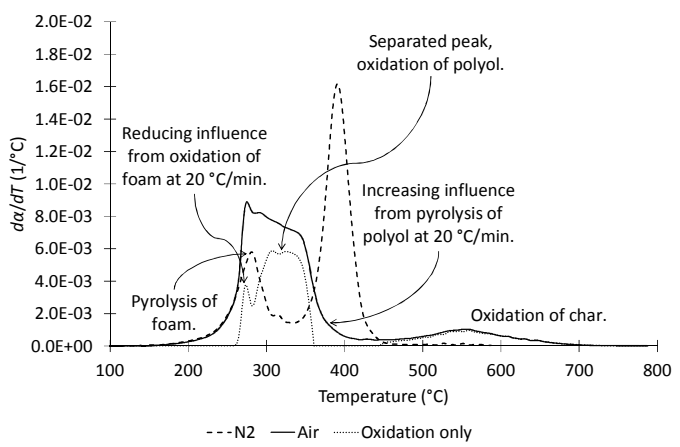

(c)

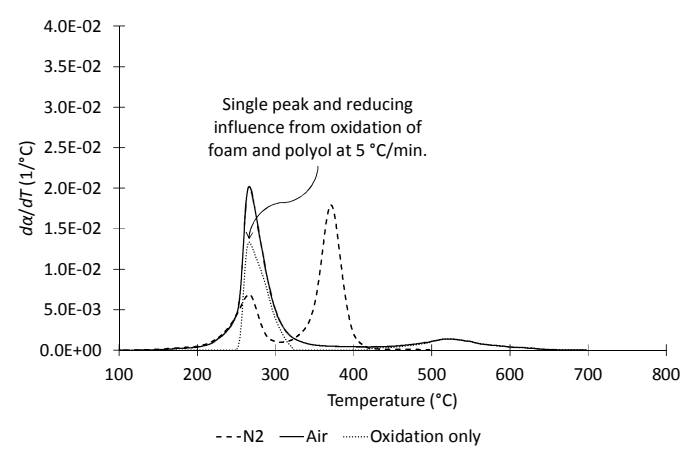

(b)

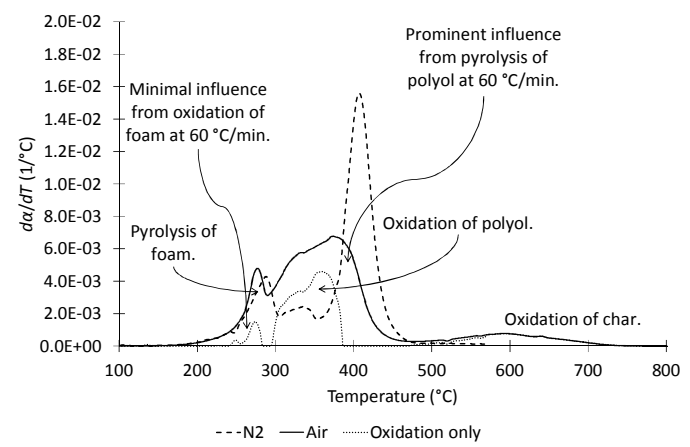

(d)

Fig. 2. Decomposition rate versus temperature of FR-Y-36 in air and nitrogen, and the derived oxidative reactions. (a) $1{ }^{\circ} \mathrm{C} / \mathrm{min}$; (b) $5{ }^{\circ} \mathrm{C} / \mathrm{min}$; (c) $20^{\circ} \mathrm{C} / \mathrm{min}$; (d) $60{ }^{\circ} \mathrm{C} / \mathrm{min}$.

\section{APPLICATION OF INFLECTION POINT METHODS}

Based on the decomposition behaviour noted in Fig. 1 and Fig. 2, the kinetic properties, $n, A$ and $E$ for the 2 pyrolysis reactions and 3 oxidative reactions for the oxidative thermal decomposition of NFR-SB-31 and FR-Y-36 are determined using the Inflection Point Methods [14]. This graphical approach has previously been applied to determine the kinetic properties for the thermal decomposition of NFR-SB-31 and FR-Y-36 in nitrogen environment [21]. These references have presented the assumptions and derivation of the graphical technique and the description of the TG results analysed, from the start of a reaction to its peak. In Eq. (1), the temperature dependent rate constant, $k$ is presented as the decomposition rate, $d \alpha / d T$ divided by the $n$th order kinetic model, $(1-$ $\alpha)^{n}$. On the right hand side, the remainder of the Arrhenius equation is in temperature basis by dividing $A$ with the heating rate, $\beta$ and $R$ is the universal gas constant, $8.314 \mathrm{~J} / \mathrm{mol} \cdot \mathrm{K}$. At the peak of a reaction or the maximum inflection point, $n=\left(E / R T^{2}\right)(1-\alpha) /(d \alpha / d T)$ and rearranging Eq. (1) yields Eq. (2) where $\Phi=T^{2}(d \alpha / d T) /(1-\alpha)$, and all inputs for $n$ and $\Phi$ are inflection point values. 


$$
\begin{aligned}
& \ln (k)=\ln \frac{d \alpha / d T}{(1-\alpha)^{n}}=-\frac{E}{R T}+\ln \left(\frac{A}{\beta}\right), \\
& \ln \left(\frac{d \alpha}{d T}\right)=\frac{E}{R}\left(\frac{\ln (1-\alpha)}{\Phi}-\frac{1}{T}\right)+\ln \left(\frac{A}{\beta}\right),
\end{aligned}
$$

The determination of the kinetic properties for the derived oxidative reactions of NFR-SB-31 at 60 ${ }^{\circ} \mathrm{C} / \mathrm{min}$ is presented in Fig. $3 \mathrm{a}-\mathrm{b}$ as an example calculation. From the plot of $\ln (d \alpha / d T)$ versus $[\ln (1-\alpha) / \Phi]-1 / T$ in Fig. 3 a, as per Eq. (2), the value of $E / R$ is determined from the slope for the $1^{\text {st }}, 2^{\text {nd }}$ and $3^{\text {rd }}$ reactions which correspond to the oxidation of foam, polyol and char, respectively. Applying $E / R$ determined into $n$ yield $37.71,10.38$ and 31.27 , respectively for these reactions. Applying $n$ found into Eq. (1), from the plot of $\ln (k)$ versus $1 / T$ in Fig. 3 b, $E$ is determined from the slope and $A$ is determined from intercept. The pair of values are $315 \mathrm{~kJ} / \mathrm{mol}$ and $1.36 \times 10^{28} 1 / \mathrm{s}$ for the $1^{\text {st }}$ reaction, $352 \mathrm{~kJ} / \mathrm{mol}$ and $6.23 \times 10^{28} 1 / \mathrm{s}$ for the $2^{\text {nd }}$ reaction, and $109 \mathrm{~kJ} / \mathrm{mol}$ and $5.98 \times 10^{10} 1 / \mathrm{s}$ for the $3^{\text {rd }}$ reaction.

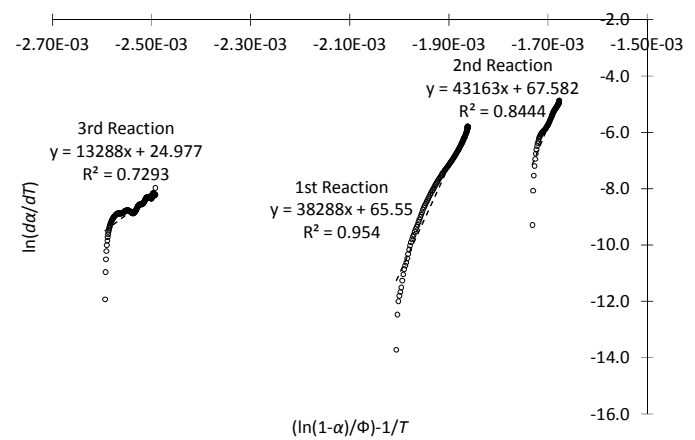

(a)

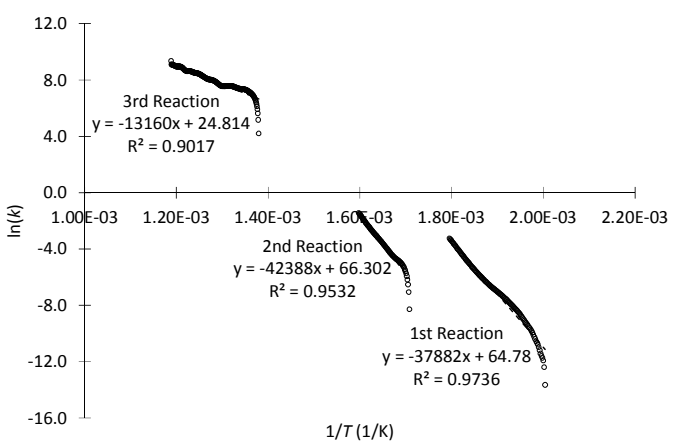

(b)

Fig. 3. Application of Inflection Point Methods on derived oxidative reactions of NFR-SB-31 at $60{ }^{\circ} \mathrm{C} / \mathrm{min}$.

(a) $\ln (d \alpha / d T)$ versus $[\ln (1-\alpha) / \Phi]-1 / T$; (b) $\ln (k)$ versus $1 / T$.

\section{KINETIC PROPERTIES AND HEAT OF REACTION}

Wang et al. [23] described a multiple-component decomposition scheme where the overall decomposition rate, $d \alpha / d t$ is the summation of the decomposition rate of each component, $(d \alpha / d t)_{i}$ based on the respective mass fraction, $c_{i}$ as per Eq. (3). This decomposition scheme is adopted as a simplified approach to model the competing pyrolysis and oxidative reactions of the heating rate dependent oxidative thermal decomposition of PU foam. Treating each reaction as a separate component, the model also contains a number of simplified assumptions, including (1) the 2 pyrolysis reactions can proceed, unaffected by the additional oxidative reactions, (2) the $c_{i}$ for each component can be reasonably estimated from the area under the curve of $d \alpha / d T$ for each reaction, and (3) the residue generated from each reaction is considered negligible. The last assumption is the least pertinent as pyrolysis and oxidation of foam is known to generate polyol; however, given there are negligible amount of residue formed following the final oxidation of char, the overall impact of this assumption is perhaps lessened.

$$
\frac{d \alpha}{d t}=\sum_{i}\left(\frac{d \alpha}{d t}\right)_{i}=\sum_{i} c_{i} A_{i} \exp \left(-\frac{E_{i}}{R T}\right)(1-\alpha)^{n_{i}},
$$


The refinement of kinetic properties introduced by Wang et al. [23] is also applied to refine $n$ and $c_{i}$ to achieve a reasonable comparison between the model and experimental $d \alpha / d T$. The refinement is qualitatively based on matching the peak values of each reaction, between the model and the experiment. Table 1 and Table 2 present the refined kinetic properties for each reaction implemented in the model where the subscript represents the different reactions, (1) oxidation of foam, (2) pyrolysis of foam, (3) oxidation of polyol, (4) pyrolysis of polyol and (5) oxidation of char. Also included in the tables is $\Delta h_{r}$ calculated from the DSC heat flow measurements, the details of this analysis are presented later in this manuscript. A few reactions with low magnitude over an extended temperature range, such as the final char oxidation, the negligible polyol pyrolysis of FRY-36 from $1-20{ }^{\circ} \mathrm{C} / \mathrm{min}$, and the negligible foam oxidation of FR-Y-36 at $60{ }^{\circ} \mathrm{C} / \mathrm{min}$, have been excluded due to difficulty in calculating the kinetic properties and modelling the reaction with reasonable accuracy. Based on the single peak observed in Fig. $2 \mathrm{a}-\mathrm{b}$, the oxidation of foam and polyol for FR-Y-36 are not differentiable at 1 and $5{ }^{\circ} \mathrm{C} / \mathrm{min}$ so these merged reactions are simply denoted by subscript (1).

Table 1. Refined kinetic properties and heat of reaction for NFR-SB-31 at all heating rates

\begin{tabular}{|c|c|c|c|c|c|}
\hline Reaction & Parameter & $1{ }^{\circ} \mathrm{C} / \mathrm{min}$ & $5^{\circ} \mathrm{C} / \mathrm{min}$ & $20^{\circ} \mathrm{C} / \mathrm{min}$ & $60^{\circ} \mathrm{C} / \mathrm{min}$ \\
\hline \multirow{4}{*}{ Foam oxidation } & $n_{1}$ & 18.50 & 20.80 & 13.00 & 22.00 \\
\hline & $A_{l}(1 / \mathrm{s})$ & $3.96 \times 10^{62}$ & $3.04 \times 10^{56}$ & $1.45 \times 10^{31}$ & $1.36 \times 10^{28}$ \\
\hline & $E_{l}(\mathrm{~kJ} / \mathrm{mol})$ & 639 & 597 & 350 & 315 \\
\hline & $c_{1}$ & 0.206 & 0.186 & 0.143 & 0.107 \\
\hline \multirow{4}{*}{ Foam pyrolysis } & $n_{2}$ & 3.50 & 4.50 & 6.58 & 9.50 \\
\hline & $A_{2}(1 / \mathrm{s})$ & $8.27 \times 10^{9}$ & $5.68 \times 10^{8}$ & $7.73 \times 10^{8}$ & $5.41 \times 10^{9}$ \\
\hline & $E_{2}(\mathrm{~kJ} / \mathrm{mol})$ & 134 & 121 & 121 & 127 \\
\hline & $c_{2}$ & 0.279 & 0.314 & 0.298 & 0.298 \\
\hline \multirow{4}{*}{ Polyol oxidation } & $n_{3}$ & 9.50 & 10.30 & 13.30 & 6.70 \\
\hline & $A_{3}(1 / \mathrm{s})$ & $1.08 \times 10^{51}$ & $3.78 \times 10^{52}$ & $4.59 \times 10^{61}$ & $6.23 \times 10^{28}$ \\
\hline & $E_{3}(\mathrm{~kJ} / \mathrm{mol})$ & 539 & 579 & 700 & 352 \\
\hline & $c_{3}$ & 0.206 & 0.267 & 0.297 & 0.298 \\
\hline \multirow{4}{*}{ Polyol pyrolysis } & $n_{4}$ & 1.04 & 0.96 & 1.20 & 1.36 \\
\hline & $A_{4}(1 / \mathrm{s})$ & $1.07 \times 10^{13}$ & $2.22 \times 10^{12}$ & $1.95 \times 10^{18}$ & $2.47 \times 10^{19}$ \\
\hline & $E_{4}(\mathrm{~kJ} / \mathrm{mol})$ & 189 & 181 & 251 & 265 \\
\hline & $c_{4}$ & 0.175 & 0.233 & 0.262 & 0.297 \\
\hline \multirow{4}{*}{ Char oxidation } & $n_{5}$ & 4.70 & excluded $^{\mathrm{a}}$ & excluded $^{\mathrm{a}}$ & excluded $^{\mathrm{a}}$ \\
\hline & $A_{5}(1 / \mathrm{s})$ & $2.34 \times 10^{44}$ & excluded $^{\mathrm{a}}$ & excluded $^{\mathrm{a}}$ & excluded $^{\mathrm{a}}$ \\
\hline & $E_{5}(\mathrm{~kJ} / \mathrm{mol})$ & 511 & excluded $^{\mathrm{a}}$ & excluded $^{\mathrm{a}}$ & excluded $^{\mathrm{a}}$ \\
\hline & $c_{5}$ & 0.134 & excluded $^{\mathrm{a}}$ & excluded $^{\mathrm{a}}$ & excluded $^{\mathrm{a}}$ \\
\hline Overall & $\Delta h_{r}(\mathrm{~J} / \mathrm{g})$ & 5499 & 4900 & 5252 & 5315 \\
\hline
\end{tabular}

${ }^{\mathrm{a}}$ Reaction has been excluded from the model.

From Table 1 and Table 2, the heating rate dependency of the oxidative reactions have resulted in greater variation in the kinetic properties across the heating rates investigated when compared with the pyrolysis reactions. From the trend of $c_{i}$, there is a notable reduction to the influence of foam oxidation as the heating rate increases while the influence of foam pyrolysis remains relatively constant. The reduction is compensated by the increase to the influence from oxidation and 
pyrolysis of polyol, particularly the latter showing notable increase at $60{ }^{\circ} \mathrm{C} / \mathrm{min}$. Figure 4 shows examples of the modelled decomposition rate for NFR-SB-31 and FR-Y-36 at specific heating rate, including the individual reactions that constitute the overall oxidative thermal decomposition.

Table 2. Refined kinetic properties and heat of reaction for FR-Y-36 at all heating rates

\begin{tabular}{|c|c|c|c|c|c|}
\hline Reaction & Parameter & $1{ }^{\circ} \mathrm{C} / \mathrm{min}$ & $5{ }^{\circ} \mathrm{C} / \mathrm{min}$ & $20^{\circ} \mathrm{C} / \mathrm{min}$ & $60^{\circ} \mathrm{C} / \mathrm{min}$ \\
\hline \multirow{4}{*}{ Foam oxidation } & $n_{l}$ & 6.10 & 22.00 & 51.00 & excluded $^{\mathrm{a}}$ \\
\hline & $A_{I}(1 / \mathrm{s})$ & $1.02 \times 10^{73}$ & $2.57 \times 10^{121}$ & $7.03 \times 10^{136}$ & excluded $^{\mathrm{a}}$ \\
\hline & $E_{l}(\mathrm{~kJ} / \mathrm{mol})$ & 753 & 1266 & 1446 & excluded $^{\mathrm{a}}$ \\
\hline & $c_{l}$ & 0.582 & 0.454 & 0.053 & excluded $^{\mathrm{a}}$ \\
\hline \multirow{4}{*}{ Foam pyrolysis } & $n_{2}$ & 2.00 & 3.10 & 4.80 & 6.70 \\
\hline & $A_{2}(1 / \mathrm{s})$ & $5.46 \times 10^{9}$ & $4.27 \times 10^{10}$ & $1.20 \times 10^{11}$ & $1.12 \times 10^{9}$ \\
\hline & $E_{2}(\mathrm{~kJ} / \mathrm{mol})$ & 130 & 137 & 141 & 118 \\
\hline & $c_{2}$ & 0.418 & 0.333 & 0.340 & 0.385 \\
\hline \multirow{4}{*}{ Polyol oxidation } & $n_{3}$ & excluded $^{\mathrm{a}}$ & excluded $^{\mathrm{a}}$ & 3.10 & 2.90 \\
\hline & $A_{3}(1 / \mathrm{s})$ & excluded $^{\mathrm{a}}$ & excluded $^{\mathrm{a}}$ & $3.80 \times 10^{14}$ & $7.37 \times 10^{10}$ \\
\hline & $E_{3}(\mathrm{~kJ} / \mathrm{mol})$ & excluded $^{\mathrm{a}}$ & excluded $^{\mathrm{a}}$ & 185 & 149 \\
\hline & $c_{3}$ & excluded $^{\mathrm{a}}$ & excluded $^{\mathrm{a}}$ & 0.394 & 0.372 \\
\hline \multirow{4}{*}{ Polyol pyrolysis } & $n_{4}$ & excluded $^{\mathrm{a}}$ & excluded $^{\mathrm{a}}$ & excluded $^{\mathrm{a}}$ & 1.91 \\
\hline & $A_{4}(1 / \mathrm{s})$ & excluded $^{\mathrm{a}}$ & excluded $^{\mathrm{a}}$ & excluded $^{\mathrm{a}}$ & $3.07 \times 10^{24}$ \\
\hline & $E_{4}(\mathrm{~kJ} / \mathrm{mol})$ & excluded $^{\mathrm{a}}$ & excluded $^{\mathrm{a}}$ & excluded $^{\mathrm{a}}$ & 331 \\
\hline & $c_{4}$ & excluded $^{\mathrm{a}}$ & excluded $^{\mathrm{a}}$ & excluded $^{\mathrm{a}}$ & 0.243 \\
\hline \multirow{4}{*}{ Char oxidation } & $n_{5}$ & excluded $^{\mathrm{a}}$ & 1.10 & 1.70 & excluded $^{\mathrm{a}}$ \\
\hline & $A_{5}(1 / \mathrm{s})$ & excluded $^{\mathrm{a}}$ & $2.46 \times 10^{9}$ & $2.56 \times 10^{10}$ & excluded $^{\mathrm{a}}$ \\
\hline & $E_{5}(\mathrm{~kJ} / \mathrm{mol})$ & excluded $^{\mathrm{a}}$ & 156 & 155 & excluded $^{\mathrm{a}}$ \\
\hline & $c_{5}$ & excluded $^{\mathrm{a}}$ & 0.213 & 0.213 & excluded $^{\mathrm{a}}$ \\
\hline Overall & $\Delta h_{r}(\mathrm{~J} / \mathrm{g})$ & 8362 & 5657 & 6045 & 6786 \\
\hline
\end{tabular}

${ }^{\mathrm{a}}$ Reaction has been excluded from the model.

Based on the sequence of the individual reactions, the modelled oxidative thermal decomposition initiates with the pyrolysis of foam, followed closely by the oxidation of foam which forms the first peak of the decomposition illustrated in Fig. 4. FR-Y-36 at $60{ }^{\circ} \mathrm{C} / \mathrm{min}$ is an exception where the oxidation of foam is excluded from the model due to minimal influence on decomposition as noted in Fig. 2 d. The modelled decomposition continues with the oxidation of polyol which forms the second peak of the decomposition for NFR-SB-31 in Fig. $4 \mathrm{a}$ and the plateau for FR-Y-36 in Fig. 4 b. FR-Y-36 at 1 and $5{ }^{\circ} \mathrm{C} / \mathrm{min}$ are exception where the oxidation of polyol is not modelled because this reaction merges with the oxidation of foam to form a single peak. Unlike the pyrolysis and oxidative reactions of foam which closely overlap, the pyrolysis of polyol occurs over higher temperature and is relatively distanced from the oxidation of polyol as seen in Fig. 4 a for NFR-SB31. FR-Y-36 from $1-20{ }^{\circ} \mathrm{C} / \mathrm{min}$ are exception where pyrolysis of polyol is not modelled due to its negligible influence on decomposition as seen in Fig. $2 \mathrm{a}-\mathrm{c}$. The pyrolysis of polyol captures the third and final peak of the main reactions. Lastly, the oxidation of char captures the extended decomposition at high temperature but this reaction is mostly excluded due to its minor contribution to the overall decomposition and the difficulty in accurately estimating its kinetic properties. 
The comparison between model and experimental decomposition rate are illustrated in Fig. 5 and Fig. 6 for NFR-SB-31 and FR-Y-36, respectively at all the heating rates investigated. The solid line represents the experimental results while the dotted line represents the model results.

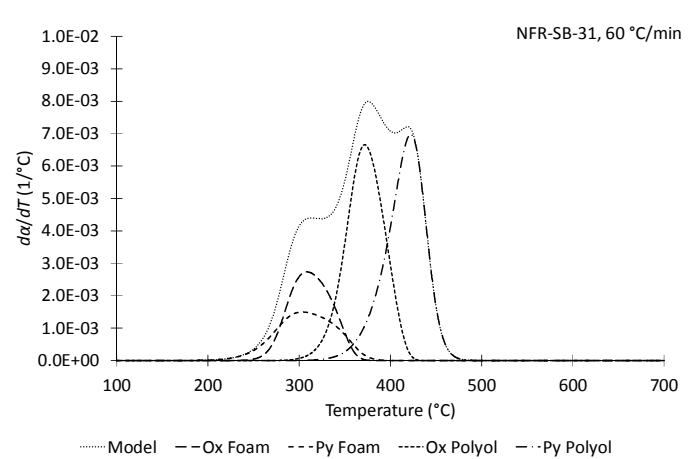

(a)

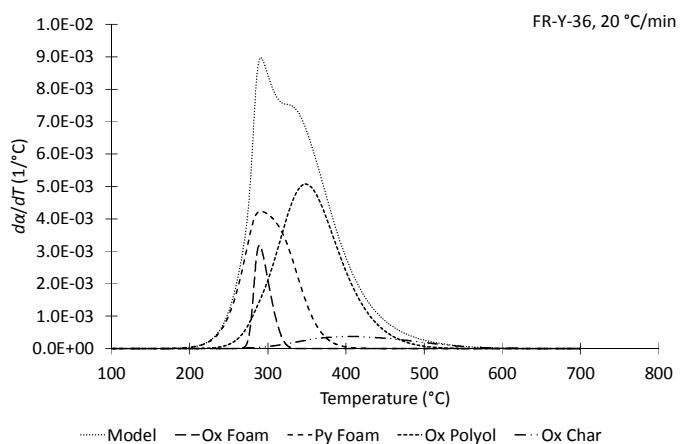

(b)

Fig. 4. Modelled decomposition rate versus temperature for oxidative thermal decomposition of PU foams. (a) NFR-SB-31 at $60{ }^{\circ} \mathrm{C} / \mathrm{min}$; (b) FR-Y-36 at $20^{\circ} \mathrm{C} / \mathrm{min}$.

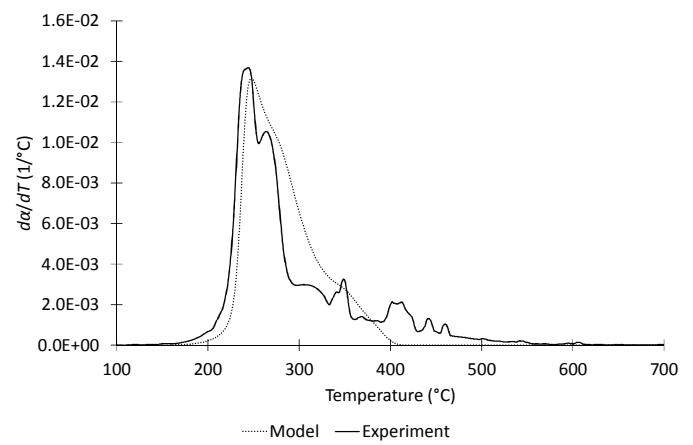

(a)

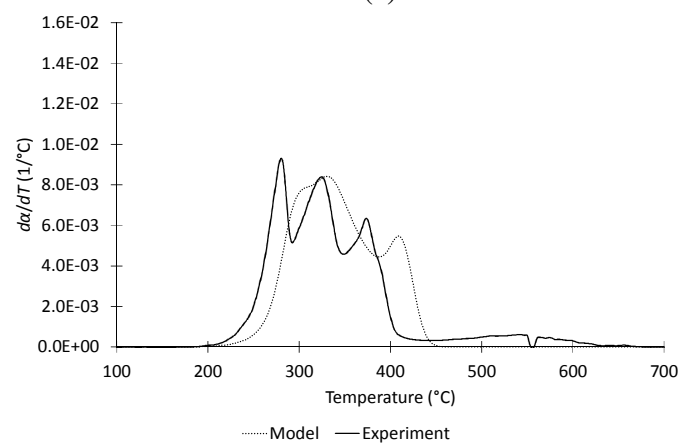

(c)

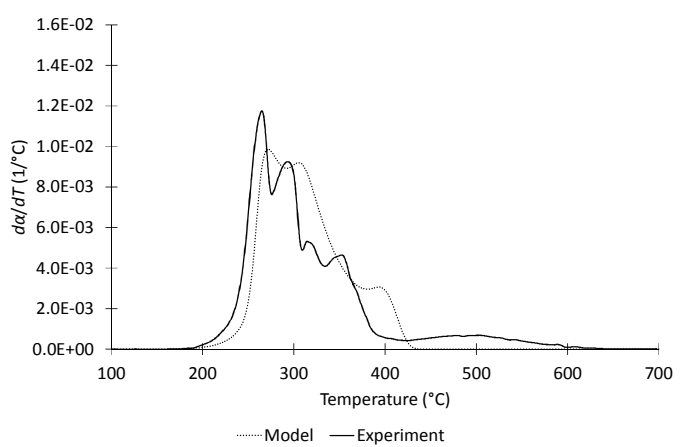

(b)

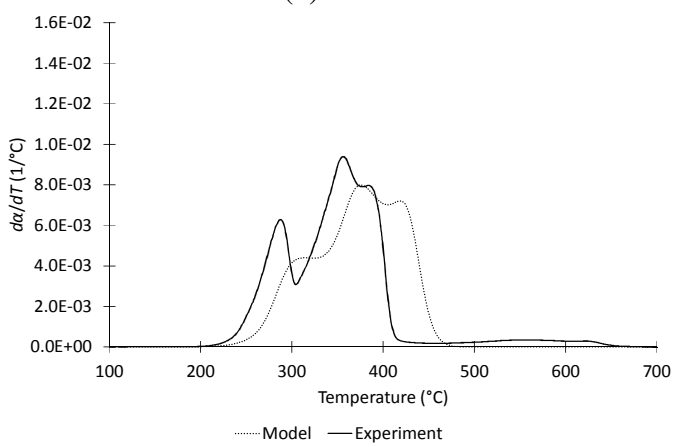

(d)

Fig. 5. Decomposition rate versus temperature between model and experiment for NFR-SB-31 in air. (a) 1 ${ }^{\circ} \mathrm{C} / \mathrm{min}$; (b) $5{ }^{\circ} \mathrm{C} / \mathrm{min}$; (c) $20^{\circ} \mathrm{C} / \mathrm{min}$; (d) $60{ }^{\circ} \mathrm{C} / \mathrm{min}$.

The simplified model is able to capture the general trend observed experimentally for oxidative thermal decomposition of foams where the maximum $d \alpha / d T$ shifts from an initial lower temperature region towards a final higher temperature region with increasing heating rate. This is due to the reduction in the influence of foam oxidation and the increase in the influence of polyol pyrolysis. Three peaks for the oxidative thermal decomposition of NFR-SB-31 are evidenced from $5-60$ 
${ }^{\circ} \mathrm{C} / \mathrm{min}$, and these are captured by the overlapping individual reactions modelled. FR-Y-36 exhibits more variation in decomposition behaviour with a single peak at $1-5^{\circ} \mathrm{C} / \mathrm{min}$ which transitions into a plateau at $20^{\circ} \mathrm{C} / \mathrm{min}$, and these features are captured by the model with reasonable accuracy. Note that the vertical scale utilised in Fig. $6 \mathrm{a}-\mathrm{b}$ is different to the others. Due to the simplified assumptions and the difficulty in accurately determining the kinetic properties of extended, low magnitude reaction, the model has not been able to capture the final stage of decomposition involving char oxidation. The model also consistently shows oxidative thermal decomposition initiating and occurring over slightly higher temperature range compared to the experiment, and such inherent mismatch is not uncommon [24]. The likely causes of mismatch include the selection of data points analysed and the adopted graphical technique to determine the kinetic properties, the assumptions made to establish the derived oxidative reactions, and the exponential nature of Arrhenius equation where minor change of inputs translate into relatively greater change of outputs.

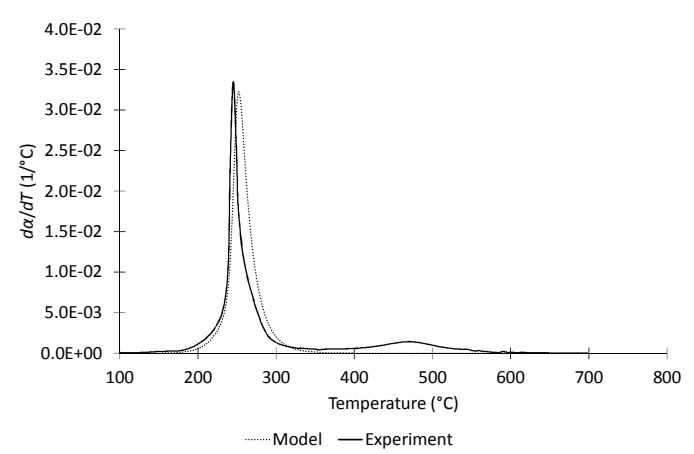

(a)

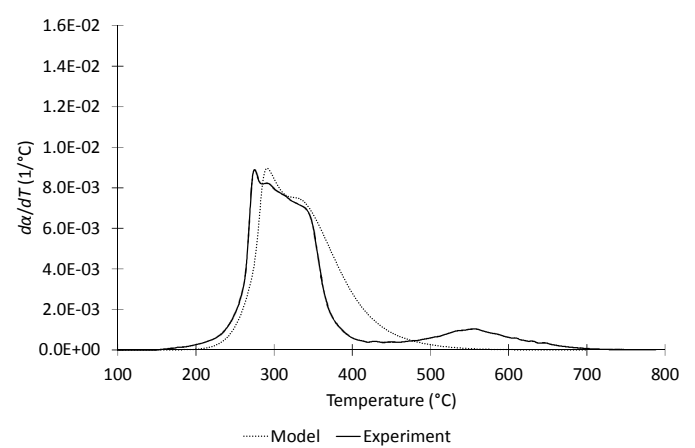

(c)

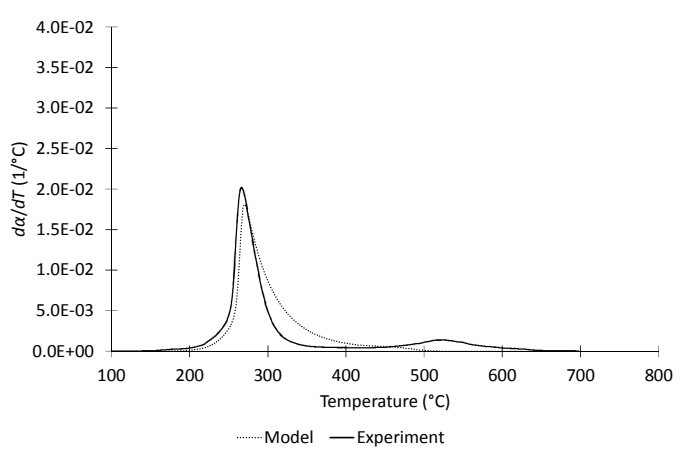

(b)

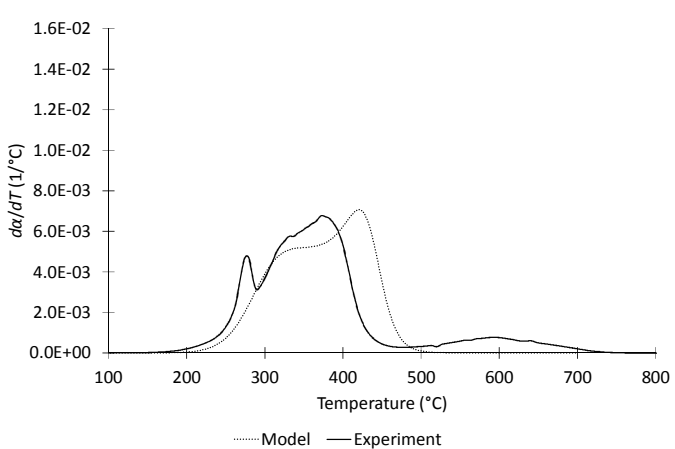

(d)

Fig. 6. Decomposition rate versus temperature between model and experiment for FR-Y-36 in air. (a) $1{ }^{\circ} \mathrm{C} / \mathrm{min}$; (b) $5{ }^{\circ} \mathrm{C} / \mathrm{min}$; (c) $20^{\circ} \mathrm{C} / \mathrm{min}$; (d) $60{ }^{\circ} \mathrm{C} / \mathrm{min}$.

Table 1 and Table 2 also presents the heat of reaction for the oxidative thermal decomposition of foams, determined from the DSC heat flow results. The method of analysis adopted has previously been applied to determine the heat of reaction for foam and polyol decomposition under inert nitrogen environment [22]. In oxidative air environment, the decomposition is exothermic in nature, releasing energy to its surrounding in lieu of endothermic where energy is absorbed for the thermal decomposition as noted under nitrogen environment. For NFR-SB-31, the exothermic heat of reaction ranges from 4900 - $5499 \mathrm{~J} / \mathrm{g}$ while for FR-Y-36, this has a higher magnitude from 5657 $8362 \mathrm{~J} / \mathrm{g}$ due to the oxidation of additional char from the fire retardant additives [4]. This amounts to approximately $19 \%$ for NFR-SB-31 and $26 \%$ for FR-Y-36, in terms of energy released during complete combustion while the remaining $81 \%$ and $74 \%$ are released in the gas phase upon 
ignition, similar to the findings in [13]. The breakdown of fire retardants within FR-Y-36 probably amount to the higher heat of reaction measured and the reduction in the amount of energy released in gas phase. The heat of reaction measured for the 2 pyrolysis reactions of foam and polyol ranges from endothermic $610-1023 \mathrm{~J} / \mathrm{g}$ and $164-295 \mathrm{~J} / \mathrm{g}$, respectively and it is evident that significantly more energy would be released than absorbed over the oxidative thermal decomposition of foam.

\section{CONCLUSIONS}

The oxidative thermal decomposition of PU foams is represented by a total of 5 reactions, 2 pyrolysis and 3 oxidative. From TG experiments, the 2 pyrolysis reactions demonstrated consistent trend with increasing heating rate while the additional 3 oxidative reactions are noted to be heating rate dependent. A simplified model is developed and applied to simulate the experimental behaviour. The model captures the essential heating rate dependent trend where the influence of foam oxidation reduces and the influence of polyol pyrolysis increases towards higher heating rate. The fire retardant additives of the FR foam, halophosphate and melamine appear to show characteristics which potentially improve the foam's fire performance. These include the notable decomposition over lower temperature region at low heating rate where the gaseous fuel released could be neutralised or diluted by the gas phase fire retardant mechanisms, and at high heating rate, the decomposition occurs over greater temperature range with lower magnitude due to char formation. However, the literature has also showed that FR foams can be prone to smouldering combustion due to the complex char formation and oxidation. The toxicity of smouldering combustion and its likelihood of transitioning into flaming combustion can diminish the fire performance of FR foams. Going forward, the research can benefit from better understanding on the impact of varying local oxygen concentration has on the oxidative thermal decomposition.

\section{ACKNOWLEDGEMENTS}

The authors would like to acknowledge the Chemistry Department for offering the experimental equipment; the lab technicians, Mr. Mike Van der Colk and Mr. Grant Dunlop for their technical support; Dr. Kai-Yuan Li for the intellectual discussions on the topic of material decomposition.

\section{REFERENCES}

[1] T.J. Ohlemiller, J. Bellan, F. Rogers, A Model of Smoldering Combustion Applied to Flexible Polyurethane Foams, Combust. Flame 36 (1979) 197-215.

[2] J.L. Torero, A.C. Fernandez-Pello, M. Kitano, Opposed Forced Flow Smoldering of Polyurethane Foam, Combust. Sci. Technol. 91 (1993) 95-117.

[3] D.C. Walther, A.C. Fernandez-Pello, D.L. Urban, Space Shuttle Based Microgravity Smoldering Combustion Experiments, Combust. Flame 116 (1999) 398-414.

[4] C.Y.H. Chao, J.H. Wang, Transition from Smoldering to Flaming Combustion of Horizontally Oriented Flexible Polyurethane Foam with Natural Convection, Combust. Flame 127 (2001) 2252-2264.

[5] G. Rein, Smouldering Combustion Phenomena in Science and Technology, Int. Rev. Chem. Eng. 1 (2009) 3-18.

[6] K. Prasad, R. Krämer, N. Marsh, M. Nyden, T. Ohlemiller, M. Zammarano, Numerical Simulation of Fire Spread on Polyurethane Foam Slabs, Proc. Fire Mater. 11 (2009) 697-708.

[7] R.H. Krämer, M. Zammarano, G.T. Linteris, U.W. Gedde, J.W. Gilman, Heat Release and Structural Collapse of Flexible Polyurethane Foam, Polym. Degrad. Stab. 95 (2010) 1115-1122.

[8] R. Bilbao, J.F. Mastral, J. Ceamanos, M.E. Aldea, Kinetics of the Thermal Decomposition of Polyurethane Foams in Nitrogen and Air Atmospheres, J. Anal. Appl. Pyrolysis 37 (1996) 69-82. 
[9] C.Y.H. Chao, J.H. Wang, Comparison of the Thermal Decomposition Behavior of a Non-Fire Retarded and a Fire Retarded Flexible Polyurethane Foam with Phosphorus and Brominated Additives, J. Fire Sci. 19 (2001) 137-156.

[10] G. Rein, C. Lautenberger, A.C. Fernandez-Pello, J.L. Torero, D.L. Urban, Application of Genetic Algorithms and Thermogravimetry to Determine the Kinetics of Polyurethane Foam in Smoldering Combustion, Combust. Flame 146 (2006) 95-108.

[11] L.B. Valencia, Experimental and Numerical Investigation of the Thermal Decomposition of Materials at Three Scales: Application to Polyether Polyurethane Foam Used in Upholstered Furniture, PhD thesis, École Nationale Supérieure de Mécanique et d'Aérotechnique, Poitiers, France, 2009.

[12] L.B. Valencia, T. Rogaume, E. Guillaume, New Method for Simulating the Kinetic of Toxic Gases Production of Upholstered Furniture Fire, Proc. Fire Mater. 11 (2009) 685-695.

[13] T. Rogaume, L.B. Valencia, E. Guillaume, F. Richard, J. Luche, G. Rein, J.L. Torero, Development of the Thermal Decomposition Mechanism of Polyether Polyurethane Foam Using Both Condensed and Gas-Phase Release Data, Combust. Sci. Technol. 183 (2011) 627-644.

[14] S.G. Viswanath, M.C. Gupta, Estimation of Nonisothermal Kinetic Parameters from a TG Curve by the Methods of Overdetermined System and Inflection Point, Thermochim. Acta 285 (1996) 259-267.

[15] H.C. Ashton, Fire Retardants, in: M. Xanthos (Ed.), Functional Fillers for Plastics, Wiley-VCH, Weinheim, 2010, pp. 309-350.

[16] S.V. Levchik, Introduction to Flame Retardancy and Polymer Flammability, in: A.B. Morgan, C.A. Wilkie (Eds.), Flame Retardant Polymer Nanocomposites, John Wiley \& Sons Inc., New Jersey, 2007, pp. 1-30.

[17] N. Grassie, G.A.P. Mendoza, Thermal Degradation of Polyether-Urethanes: Part 4 - Effect of Ammonium Polyphosphate on the Thermal Degradation of Polyether-Urethanes Prepared from Methylene Bis(4-Phenylisocyanate) and Low Molecular Weight Poly(Ethylene Gylcols), Polym. Degrad. Stab. 11 (1985) 145-166.

[18] D. Price, Y. Liu, G.J. Milnes, R. Hull, B.K. Kandola, A.R. Horrocks, An Investigation into the Mechanism of Flame Retardancy and Smoke Suppression by Melamine in Flexible Polyurethane Foam, Fire Mater. 26 (2002) 201-206.

[19] C. Denecker, J.J. Liggat, C.E. Snape, Relationship between the Thermal Degradation Chemistry and Flammability of Commercial Flexible Polyurethane Foams, J. Appl. Polym. Sci. 100 (2006) 3024-3033.

[20] D.S.W. Pau, A Comparative Study on Combustion Behaviours of Polyurethane Foams with Numerical Simulations using Pyrolysis Models, PhD thesis, University of Canterbury, Christchurch, New Zealand, 2013.

[21] D.S.W. Pau, C.M. Fleischmann, M.J. Spearpoint, K.Y. Li, Determination of Kinetic Properties of Polyurethane Foam Decomposition for Pyrolysis Modelling, J. Fire Sci. 31 (2013) 356-384.

[22] D. Pau, C. Fleischmann, M. Spearpoint, K.Y. Li, Sensitivity of Heat of Reaction for Polyurethane Foams, In: Nilsson, D., van Hees, P., Jansson, R. (Eds.), Fire Safety Science-Proceedings of the Eleventh International Symposium, pp, 179-192, 2014.

[23] X. Wang, C.M. Fleischmann, M.J. Spearpoint, Parameterising Study of Tunnel Experiment Materials for Application to the Fire Dynamics Simulator Pyrolysis Model, J. Fire Sci. 34 (2016) 490-514.

[24] F. Hache, M. Delichatsios, T. Fateh, J. Zhang, Comparison of Methods for Thermal Analysis: Application to PEEK and a Composite PEEK + CF, J. Fire Sci. 33 (2015) 232-246. 